\title{
UNA ENCUESTA EXPLORATORIA PARA CUANTIFICAR LA INFLUENCIA DE LAS REDES SOCIALES EN LAS RUTINAS PROFESIONALES DE LOS PERIODISTAS ECUATORIANOS: REFLEXIONES SOBRE LA MEDIAMORFOSIS DEL ECUADOR (2014)*
}

\author{
An Exploratory Survey to Quantify the Influence of Social Networks in \\ the Professional Routines of Ecuadorian Journalists: Reflections on the \\ Mediamorphosis from Ecuador (2014)
}

\section{Uma enquete exploratória para quantificar a influência das redes sociais nas rotinas profissionais dos periodistas equatorianos: reflexões sobre a midiamorfose do Equador (2014)}

* El presente trabajo ha sido realizado gracias a los aportes humanos y materiales de la Universidad de las Américas (Ecuador), y de CIESPAL (Ecuador), durante la gestión del Dr. Fernando Checa (hasta junio de 2014). Asimismo, forma parte del proyecto Audiencias Activas y Periodismo: Estrategias de Innovación para la Empresa Informativa y Nuevas Figuras Profesionales (CSO2012-39518-C04-04), financiado por el Ministerio de Economía y Competitividad de España (2012-2015). Algunos de sus resultados fueron mostrados bajo el título Las redes sociales como fuentes informativas y como plataformas de interacción con las audiencias: los retos del periodismo ecuatoriano frente a las nuevas tecnologías (2014) en el evento Periodismo en Debate, organizado por la Universidad San Francisco de Quito durante el mes de noviembre de 2014. 
BARREDO IBÁÑEZ, Daniel. Universidad de las Américas (Ecuador)

danielbarredo@aol.com

PALOMO, Bella. Universidad de Málaga (España)

bellapalomo@uma.es

MANTILLA, Adriana. Universidad Central del Ecuador (Ecuador)

adrianagarridom@gmail.com

GARD, Constance. Sciences Po Grenoble (Francia)

c.gard@hotmail.fr

\section{Fecha de recibido: 4 de noveimbre de 2014}

Fecha de aceptado: 4 de marzo de 2015

\section{RESUMEN}

La expansión de la web 2.0, basada en la aceptación de la inteligencia colectiva, está estimulando, a nivel global, una revolución en las formas de gestionar la información. Se trata de un escenario donde se imponen algunas alteraciones dentro de la profesión periodística: el informador se convierte en un gatewatcher, en un observador de los contenidos simbólicos que originan las audiencias, más que en el tradicional gatekeeper, es decir, el filtro que determinaba lo que había que publicar. En esta nueva mediamorfosis, los medios de comunicación se están convirtiendo en puntos de encuentro donde los ciudadanos acuden para dialogar entre sí. Sin embargo, Ecuador plantea determinados retos que dificultan el desarrollo del periodismo participativo. Retos que van desde los planteamientos normativos (tras la aprobación de la Ley Orgánica de Comunicación), la baja conectividad de la sociedad a Internet, e incluso algunos factores socioculturales, como la baja participación de los ciudadanos ecuatorianos en el espacio público. En este artículo se muestran los resultados de una encuesta nacional dirigida a periodistas de los principales medios ecuatorianos con objeto de conocer la influencia que las redes sociales poseen en sus rutinas profesionales diarias. Los resultados señalan una baja interacción de los periodistas encuestados con sus audiencias, así como una limitada integración de los contenidos amateur dentro de los contenidos periodísticos. A modo de conclusión, anotamos la adherencia a las rutinas off-line en las rutinas online, junto con un parcial desconocimiento de la potencialidad que tiene la participación ciudadana para la transformación del periodismo del siglo XXI.

Palabras clave: Periodismo ecuatoriano, redes sociales, participación ciudadana, interactividad, Ley Orgánica de Comunicación. 


\section{ABSTRACT}

The expansion of Web 2.0, based on the acceptance of collective intelligence, is stimulating a global revolution in the ways of information management. This is a scenario where some alterations within the journalistic profession are imposed: the reporter becomes a gatekeeper, an observer of the symbolic content that originates from readers, rather than the traditional gatekeeper, i.e. a filter that determines the content that is necessary to post. In this new mediamorphosis, the media are becoming meeting places where people come to talk to each other. However, Ecuador poses certain challenges that hinder the development of a participatory journalism, including regulatory regimes (after the adoption of the Communications Law in 2013), low connectivity to the Internet, and even some sociocultural factors, such as low participation of Ecuadorian citizens in the public space. This article presents the results of a national survey of journalists from major Ecuadorian print and electronic media, with the goal of shedding light on the influence social networks have on those journalists' daily routines. The results indicate a low interaction between reporters and their audiences, along with a partial ignorance of the potential that citizen participation has in the transformation of journalism.

Keywords: Ecuadorian journalism, social networks, citizen participation, interactivity, Communications Law.

\section{RESUMO}

A expansão da web 2.0, baseada na aceitação da inteligência coletiva, está estimulando, no nível global, uma revolução nas formas de gestar a informação. Trata-se de um cenário onde se impõem algumas interações dentro da profissão jornalística: o informador converte-se em um gatewatcher, em um observador dos conteúdos simbólicos que originam as audiências, mais que no tradicional gatekeeper, é dizer, o filtro que determinava o que devia se publicar. Nesta nova midiamorfose, os meios de comunicação estão-se convertendo em pontos de encontro onde os cidadãos acodem para dialogar entre si. No entanto, Equador apresenta determinados desafios que dificultam o desenvolvimento do jornalismo participativo. Desafios que vão desde as abordagens normativas (depois da aprovação da Lei Orgânica de Comunicação), a baixa conectividade da sociedade a Internet, e inclusive alguns fatores socioculturais, como a baixa participação dos cidadãos equatorianos no espaço público. Neste artigo mostram-se os resultados de uma enquete nacional dirigida a jornalistas dos principais meios equatorianos com objeto de conhecer a influência que as redes sociais possuem em suas rotinas profissionais diárias. Os resultados assinalam uma baixa interação dos jornalistas pesquisados com suas audiências, assim como uma limitada integração dos conteúdos amateur dentro dos conteúdos jornalísticos. A modo de conclusão, anotamos a aderência às rotinas off-line nas rotinas on-line, junto com um parcial desconhecimento da potencialidade que tem a participação cidadã para a transformação do jornalismo do século XXI.

Palavras-chave: Jornalismo equatoriano, redes sociais, participação cidadã, interatividade, Lei Orgânica de Comunicação.

\section{4}




\section{Introducción}

La participación ciudadana en la ciberesfera de América Latina se enfrenta a varios problemas contextuales. Entre las sociedades latinoamericanas hay diferentes "brechas" en el uso de Internet, motivadas por la falta o las deficiencias de las infraestructuras que permiten el acceso a la información digital, según explican Hawkins y Hawkins (2003, p. 659). Dentro de esas brechas, a comienzos de la primera década del siglo XXI, encontramos por ejemplo un polo representado por Chile, con una tasa de 167 usuarios que se conectan a Internet por cada 1000 personas, seguido de Uruguay -111 usuarios de Internet por cada 1000 personas-, en tanto que hay otro polo de subutilización abanderado por Cuba, con 5 usuarios de Internet por cada 1000 personas, o Guatemala y Paraguay, con 7 usuarios de Internet por cada 1000 personas. En 2010, la banda ancha alcanzaba al 6,8 \% de la población latinoamericana (Katz \& Ávila, 2011, p. 10), mientras que la tasa de los países occidentales, en ese mismo año - según la misma fuente-fluctuaba entre el $24 \%$ y el $30 \%$ de los usuarios. En 2013, el número de abonados a banda ancha de América Latina rozaba los 9,1 usuarios por cada 100 personas, frente a los 9,5 de la media mundial, o los 29 usuarios de cada cien habitantes de la media de la Unión Europea (Banco Mundial, s.f.). En cambio, la tasa de conexión a teléfonos celulares sobrepasaba la media mundial en la región latinoamericana, y se acercaba a la media europea, según puede observarse en la siguiente gráfica:

\section{Gráfica 1. Comparativa de abonados a celulares por cada 100 personas (2004-2013)}

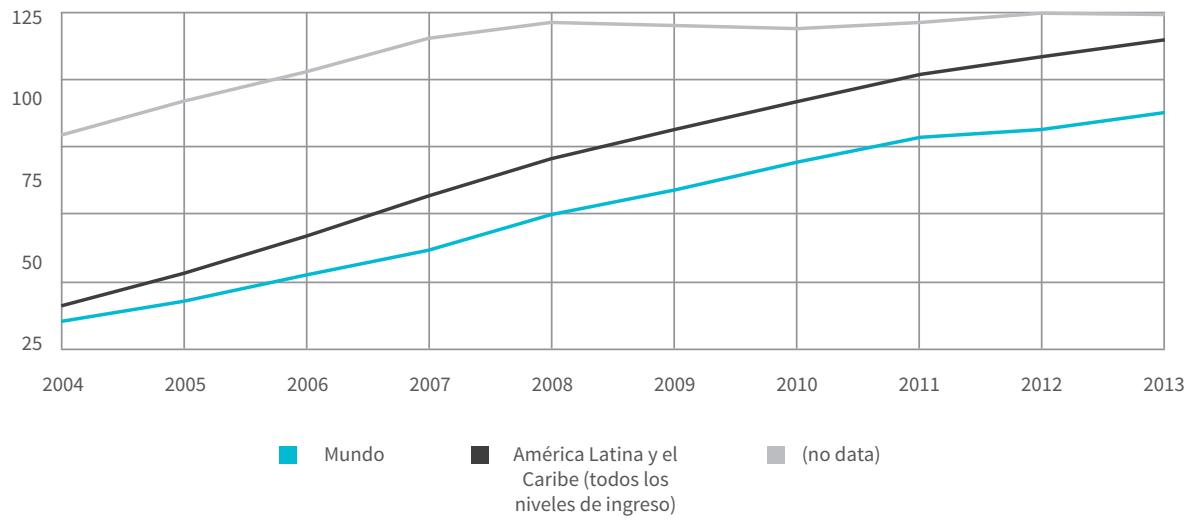

Fuente: Banco Mundial (s.f.).

Sin embargo, y en paralelo a la infrautilización de las posibilidades digitales de algunos de los países, la región se erige como una de las zonas del mundo donde ha crecido más rápidamente el uso de Internet (Holdom, 2005), circunstancia beneficiada por la expansión económica del continente americanoํ․ Desde el punto de vista estric-

1 Según un informe de la agencia publicitaria Nazca Saatchi \& Saatchi, la expansión de lo digital es tal que los latinoamericanos multiplican por dos la media mundial de acceso a Internet (cit. por Holdom, 2005, p. 353). 
tamente académico, hay problemas de acceso a la información, ya que hasta fechas recientes las contribuciones se almacenaban únicamente de forma tradicional:

Hasta hace muy poco, la referencia de Internet como fuente en los estudios latinoamericanos era una forma de acceder a gigabytes de información sobre los últimos eventos (diarios, asuntos actuales de revistas populares, viajes e información turística, alertas sobre derechos humanos y políticos, información básica sobre los gobiernos), pero solo facilitaba un limitado acceso a archivos de noticias más profundas o a recursos académicos². (Molloy, 2005, p. 145)

Esa conservación de las contribuciones académicas en surtidores tradicionales, auguraba una invisibilización parcial de los trabajos publicados en esta área de estudio ${ }^{3}$, problemática a la que hay que sumar las dificultades de los investigadores latinoamericanos para mostrar sus producciones en revistas internacionales de referencia (cit. por Holdom, 2005, p. 355).

La educación superior en Ciencias de la Información o Comunicación, en menos de veinte años, ha crecido en la región hasta casi triplicar la oferta académica: de 1984 a 2002, según Hughes y Lawson (2005, p. 20), la región pasó de 181 "programas" a los 402; si bien la organización de esos programas lastra parte de las falencias contextuales, como por ejemplo la inadaptación a las nuevas soluciones de participación.

Por todos estos factores los estudios sobre la actividad de las audiencias en América Latina carecen de una importancia singular, en comparación con los de otras zonas del globo, donde consumo, educación e investigación se funden para abanderar y representar nuevas tendencias y opciones. A grandes rasgos, podría definirse la situación latinoamericana como en fase de desarrollo comunicacional, a pesar de la creciente corriente de estudios académicos preocupados por definir qué vías ofrecen los cibermedios a la participación ciudadana, sea como un objeto concreto, o como un objeto integrado junto a otras variables de análisis, como demuestran los trabajos de Díaz (2000); Morales (2000); Palacios, Mielniczuk, Ribas y Narita (2002); Chirinos (2006); Yezers'ka (2006); Hernández, López y Pereira (2007); Milena (2007); Yezers'ka (2008); Said y Arcila (2011b); Said, Arcila y Méndez (2011); Gutiérrez y Páez (2012); Said y Valencia (2012); Said y Arcila (2012). Hay, asimismo, otra interesante línea de estudios que indagan sobre las posibilidades de las plataformas digitales en la región latinoamericana (Franco \& Guzmán, 2004, 22 de abril; Islas, 2006; López Aguirre, 2009; Said \& Arcila, 2011a), en paralelo a esas otras contribuciones relacionadas con el análisis de la gestión de las redes sociales en América Latina (Said \& Arcila, 2011c; Harlow \& Harp, 2012), o a los estudios de reflexión que promueven una mayor interacción con las audiencias, o que se cuestionan las transformaciones latinoamericanas en función de esas posibilidades digitales (Navarro, 2002; Jódar Marín, 2010; Barredo, 2013b).

Lo cierto es que estos estudios reflejan que en América Latina hay un interés compartido por analizar las transformaciones que está sufriendo el espacio público contemporáneo, la conversión de la gestión simbólica en

2 Traducción propia. La cita original es: "Until very recently, the Internet as a reference source for Latin American Studies was a way to access gigabytes of information on the latest events (daily newspapers, current issues of popular magazines, travel and tourism information, political and human rights alerts, basic government information) but provided only limited access to deep news archives or scholarly resources".

3 La puesta en marcha de iniciativas como SciELO o RedALyc, publicaciones digitales gratuitas, puede mitigar en los próximos años la problemática aludida, según explica Molloy (2005, p. 146). 
un fenómeno multipolar y participativo, algo que ya defendimos en algunos trabajos anteriores (Oller \& Barredo, 2012; Barredo, Oller \& Buenaventura, 2013).

Las sociedades latinoamericanas cuentan con algunos condicionantes que dificultan el impulso de las nuevas rutinas o roles periodísticos, como el paso del gatekeeping o filtración, hacia el gatewatching u observación de los contenidos (Bruns, 2008). Entre esos condicionantes, destaca la ola reguladora que se ha gestionado de forma generalizada (Ávila, 2013), la cual en algunos casos - como anotaremos más adelante, al referirnos al contexto ecuatoriano- omite un intento de afrontar los problemas legales característicos del periodismo digital contemporáneo, como el conflicto sobre quién es el responsable de las aportaciones ciudadanas en los cibermedios (Singer \& Ashman, 2009), o la cuestión del copyright o beneficiario principal de esas aportaciones (Deuze, 2001). Pero en cualquier caso, los periodistas latinoamericanos son cada vez más conscientes de la creciente importancia de la interacción ${ }^{4}$ con las audiencias, como demuestra un estudio de Schmitz y de Macedo (2009) basado en la realización de un grupo focal con informadores de América Latina, EE.UU. y Europa:

Un periodista del norte de Brasil sugirió que el modelo informativo del siglo XXI estaría en que 'la audiencia participará en el proceso de construcción de las noticias.' Otro periodista latinoamericano, de México, sugirió que su diario digital está intentando hacer dos cosas, 'difundir información en tiempo real, profundizada con recursos multimedia, y convertir nuestro sitio en la plaza de una ciudad, una plaza donde la comunidad se habla a sí misma', sugiriendo pocas interferencias de los propios periodistas en este proceso de comunicación entre ciudadanos5. (Schmitz y de Macedo, 2009, p. 594)

Reflexiones como la anterior denotan la importancia otorgada a la integración de los usuarios en las plataformas informativas. No es solo una consecuencia de la democracia, sino también dependiente de la maduración de los mercados latinoamericanos, es decir, la constante "homogeneización" que Boczkowski y de Santos (2007, p. 176) observaron en los ciberdiarios argentinos, dada la extremada competencia que se establece entre las cabeceras digitales.

\subsection{Una panorámica del contexto ecuatoriano}

Ecuador es un país marcado por la brecha digital: según un informe de la Corporación Andina de Fomento, dentro de los niveles de desarrollo de infraestructura de telecomunicaciones Ecuador se situaba en 2010 en un nivel en desarrollo, con una penetración promedio de telefonía celular del 99,47\% y del 7,62\% de banda ancha (Katz \& Ávila, 2011, p. 12). En 2013, apenas cuatro de cada diez ecuatorianos tenían acceso a Internet (Ministerio de Telecomunicaciones y de la Sociedad de la Información, 2014, 19 de mayo). La brecha, como señalan Torres e Infante (2011, p. 87), está inextricablemente ligada a "la realidad socioeconómica" del país, esto es, a las fuertes diferen-

4 Es una oportunidad de intercambio que puede darse de individuo a individuo, de individuo a computador, o entre un individuo y un contenido, según McMillan (cit. por Steensen, 2011, p. 316).

5 Traducción propia. La cita original es: "A journalist from northern Brazil suggested that the news model for the 21st century would be 'the audience will participate in the process of construction of the News'. Another Latin American journalist, from Mexico, suggested that his online newspaper is trying to do two things, 'Bring them real time information, enhanced with multimedia and converting our site into a town square, a place where the community talks to itself', suggesting little interference by the journalists themselves in this communication process among citizens". 
cias entre los entornos urbanos y los entornos rurales, e incluso a las propias diferencias que hay también dentro de esos mismos entornos.

Los orígenes del periodismo digital en el país andino se remontan a 1995, según Diana Rivera (2011, p. 3), con algunas iniciativas pioneras iniciadas por el desaparecido diario Hoy. José Rivera, en cambio, sitúa el nacimiento del Hoy digital - precursor de los ciberdiarios ecuatorianos- a finales de 1994 (Rivera, 2013, p. 112). Esa divergencia sobre un punto tan esencial que alude a la historia del enclave periodístico digital de Ecuador, señala las dificultades a las que se enfrenta el investigador de ese tipo de medios en el país andino: hay una falta de estudios que ofrezcan datos estables que permitan estructurar panorámicamente la situación. Dichas dificultades son extrapolables también a otros soportes, ya que la ausencia de material bibliográfico investigativo coincide con una abundancia de "libros de carácter anecdótico" (Punín \& Calva, 2014, p. 22) que confunden más de lo que explican.

Para un país que concentra algunas dificultades severas en el desarrollo social, y un porcentaje escaso de usuarios que se conectan a Internet, hay cierta diversidad de medios digitales: "[En el contexto ecuatoriano] Existe un total de 34 medios de comunicación nativos digitales, 16 periódicos digitales, 14 radios y cuatro revistas" (Rivera, 2013, p. 117). De una forma bastante similar, en otro estudio se contabilizaron 17 medios digitales (Coronel, Mier, Barrazueta et ál., 2012), luego los condicionantes hay que buscarlos en aspectos como la calidad de esos medios, más que en la abundancia de la oferta. Dentro de esas deficiencias, algunos autores han criticado la escasa capacidad de los medios ecuatorianos para crear comunidades (Punín, Martínez \& Rencoret, 2014). Tanto los medios como las audiencias se ven severamente afectados por la adherencia a rutinas off-line que determinan a las rutinas online, como la falta general de participación ciudadana en la esfera pública (Paredes, 2011), la cual está influenciada por la existencia de ciertas "estructuras discriminatorias" (Sánchez, 2008, p. 231) que tienden a rechazar la integración efectiva de la opinión individual dentro del círculo colectivo. Es cierto que, a partir de los sucesivos gobiernos de Rafael Correa, se han activado algunas iniciativas que impulsan una transformación de los patrones sociales; pongamos por ejemplo el Plan Nacional para el Buen Vivir (Senplades, 2013), cuyos objetivos persiguen, entre otros, una profundización del sentido de la democracia.

Desde el punto de vista comunicacional, el impulso reformista de la llamada Revolución Ciudadana cristalizó en la aprobación en 2013 de la Ley Orgánica de Comunicación (LOC), un instrumento jurídico puesto en marcha por el Estado ecuatoriano para recuperar la iniciativa en el paradigma mediático (Ramos, 2013). Sus supuestos normativos, que fueron desarrollados al calor de unas enormes expectativas, han generado un desencanto en multitud de organizaciones sociales y profesionales (Ramos \& Gómez, 2014). No vamos a entretenernos con la descripción de los motivos de tal desencanto; pero quizá el aspecto que más interesa a este análisis es la falta de una regulación precisa en ámbitos clave para la comunicación del siglo XXI, como son las redes sociales: si el artículo 3 de la LOC incluye la reglamentación de los medios en Internet, el artículo 2 excluye del control "los contenidos que formulen los ciudadanos y las personas jurídicas en sus blogs, redes sociales y páginas web personales, corporativas o institucionales".

Ante este panorama, el crecimiento exponencial de las redes sociales en Ecuador obliga a los legisladores de ese país a afrontar algunas implementaciones o mejoras sobre el texto jurídico: solo en Facebook, entre 2011 y 2014, el número de usuarios ha pasado de 2,8 millones a 7 millones (Elcomercio.com, 2014, 17 de agosto). Unas implementaciones que, en cualquier caso, aún no se han dado. 


\subsection{Preguntas de investigación}

Las páginas que siguen se han orientado en función de tres preguntas de investigación:

1. ¿Qué tipo de formación especializada sobre comunicación digital recibían los periodistas ecuatorianos en 2014 ?

2. ¿Cuál era el uso que tendía a darse a las redes sociales dentro de la cultura periodística ecuatoriana?

3. ¿En qué medida las redes sociales influenciaban la construcción periodística de la realidad en Ecuador?

Con estas preguntas, se pretende obtener información tanto de la capacitación que recibían globalmente los periodistas del Ecuador en redes sociales, como en aspectos vinculados a la implementación de dichas redes en el ejercicio periodístico.

\section{Metodología}

Para desarrollar este estudio exploratorio y cumplir con los anteriores objetivos, se elaboró una encuesta, técnica cuantitativa muy utilizada en el ámbito de las Ciencias Sociales (Ander-Egg, 1993; Hueso \& Cascant, 2012). La encuesta, entre otros beneficios, permite adentrarse en fenómenos complejos con una inversión escasa de recursos económicos (Asa Berger, 2014), a pesar de que la fuente citada destaca también algunos peligros, como el hecho de que las personas encuestadas, por ejemplo, no entiendan las interrogantes.

El cuestionario a través del cual se viabilizó la encuesta se elaboró a partir de una cuidadosa revisión de la literatura relacionada con los siguientes ejes:

a. Las características y las particularidades de la influencia de las redes sociales en el ejercicio periodístico.

b. Las experiencias del uso de las redes sociales por parte de periodistas sobre todo en el contexto latinoamericano.

c. El uso de Internet y de las redes sociales en Ecuador.

d. Los factores que determinan las particularidades de la cultura periodística ecuatoriana.

En total, se prepararon 35 preguntas divididas en función de los bloques temáticos definidos desde los tres objetivos de la investigación. Durante el mes de marzo de 2014 se realizó la fase pretest, en la cual se comprobó la claridad y la pertinencia de las interrogantes, así como otras cuestiones tendentes a generar una mayor estabilidad instrumental, según suele aconsejarse en los proyectos que cuentan como técnica de investigación a la encuesta (Meso \& Palomo, 2012; Barredo, 2013a; Asa Berger, 2014; Sánchez \& Palomo, 2014). Dicha fase se dividió en dos partes esenciales, las cuales se articularon como prueba de validez de contenido:

a. Fase 1: el Dr. Martín Oller (investigador en el Instituto de Altos Estudios Nacionales, Ecuador), y la MsC. María del Carmen Cevallos (docente e investigadora en la Pontificia Universidad Católica del Ecuador) evaluaron aspectos de legibilidad y de profundidad del cuestionario.

b. Fase 2: se testó el instrumento ante un grupo estratégico: se recopiló la opinión de los 19 asistentes al taller La cultura periodística intermedia de América Latina: un proyecto de investigación internacional comparativo, impartido a finales de marzo de 2014 en la sede de CIESPAL (Quito, Ecuador).

La falta de un censo nacional de periodistas ecuatorianos determinó la necesidad de diseñar un muestreo de conveniencia de "tipo estratégico" (Corbetta, 2007, p. 288). El mayor problema de este tipo de muestreo es que 
los resultados impiden su generalización (Hernández, 2004), por lo que su aplicación se aconseja para estudios donde -como en las páginas que siguen - predomine un carácter exploratorio. El cuestionario, organizado dentro de Surveymonkey.com, fue difundido vía correo electrónico a una población aproximada de 400 periodistas que trabajaban en 2014 en medios de comunicación de alcance nacional, independientemente del soporte (radio, televisión, prensa o medios digitales). La muestra fue tomada desde las bases de datos y directorios de periodistas nacionales de Ecuador archivadas por el área de Comunicación Corporativa del Centro Internacional de Estudios Superiores de Comunicación para América Latina, una de las principales instituciones académicas - radicada en Quito, Ecuador- vinculadas al estudio de la Comunicación en la región latinoamericana, según describen Barredo y Porto (2014). La encuesta estuvo activa en línea entre los meses de abril y mayo de 2014, y los encuestadores contactaron hasta tres veces con los integrantes de la muestra a través de un correo electrónico estandarizado a modo de recordatorio.

\subsection{Muestra}

Se consiguieron un total de 38 opiniones procedentes de periodistas de medios de orientación nacional, de los que un 73,68\% (n=28) tenía algún tipo de título vinculado a la Comunicación o al Periodismo, frente a un 26,32\% $(\mathrm{n}=10)$ que bien carecía de título académico, bien estaban relacionados con otras áreas de estudio:

Tabla 1. Descripción de los encuestados

\begin{tabular}{|c|c|c|}
\hline Variable & Frecuencia & $\%$ \\
\hline Sexo & 38 & 100 \\
\hline Hombres & 23 & 60,53 \\
\hline Mujeres & 15 & 39,47 \\
\hline Educación & 38 & 100 \\
\hline Primaria & 0 & 0 \\
\hline Secundaria & 0 & 0 \\
\hline Licenciatura / ingeniería & 26 & 68,42 \\
\hline Maestría & 8 & 21,05 \\
\hline Doctorado & 1 & 2,63 \\
\hline Otros & 3 & 7,89 \\
\hline Edad & 38 & 100 \\
\hline De 18 a 25 años & 5 & 3,16 \\
\hline De 26 a 35 años & 19 & 50 \\
\hline De 36 a 45 años & 9 & 23,68 \\
\hline De 46 a 55 años & 2 & 5,26 \\
\hline
\end{tabular}




\begin{tabular}{|c|c|c|}
\hline Variable & Frecuencia & $\%$ \\
\hline Más de 55 años & 3 & 7,89 \\
\hline Zona de residencia & 38 & 100 \\
\hline Zona 1 (Esmeraldas, Imbabura, Carchi, Sucumbíos) & 0 & 0 \\
\hline Zona 2 (Pichincha, Napo, Orellana) & 7 & 18,42 \\
\hline Zona 3 (Cotopaxi, Tungurahua, Chimborazo, Pastaza) & 0 & 0 \\
\hline Zona 4 (Manabí, Santo Domingo de los Tsáchilas) & 0 & 0 \\
\hline Zona 5 (Santa Elena, Guayas , Bolívar, Los Ríos y Galápagos) & 1 & 2,63 \\
\hline Zona 6 (Cañar, Azuay, Morona Santiago) & 1 & 2,63 \\
\hline Zona 7 (El Oro, Loja, Zamora Chinchipe) & 0 & 0 \\
\hline Zona 8 (Guayaquil, Samborondón y Durán) & 4 & 10,53 \\
\hline Zona 9 (Distrito Metropolitano de Quito) & 25 & 65,79 \\
\hline
\end{tabular}

Fuente: elaboración propia.

En líneas generales, casi seis de cada diez encuestados, esto es, el 52,63\% $(n=20)$ trabajaban en medios impresos, mientras que el $15,79 \%(n=6)$ se desempeñaba en radio; e iguales porcentajes obtuvieron quienes laboraban en televisión ( $n=6)$, y quienes ejercían en medios digitales $(n=6)$.

\section{Resultados}

\subsection{Formación especializada}

La capacitación de los informadores, en el ámbito de la gestión de las redes, se ha subrayado como un aspecto "clave" para evitar la denominada "miopía informativa" (Palomo, 2013, p. 116). Sin embargo, en el caso ecuatoriano, cuatro de cada diez encuestados, es decir, el 42,11\% ( $\mathrm{n}=16 ; \mathrm{x}=0,42 ; \sigma=0,500)$ no había realizado ningún tipo de formación especializada sobre la gestión de las redes sociales. Sin embargo, algunos de los periodistas había recibido tanto cursos presenciales, como cursos virtuales: un 52,63\% ( $\mathrm{n}=20 ; \mathrm{x}=0,53 ; \sigma=0,506)$ marcó la primera opción, en tanto que un $15,79 \%(n=6 ; x=0,16 ; \sigma=0,370)$ se decantó por la segunda. 


\section{Gráfica 2. Tipos de formación especializada en redes sociales en Ecuador, según los periodistas encuestados (2014)}

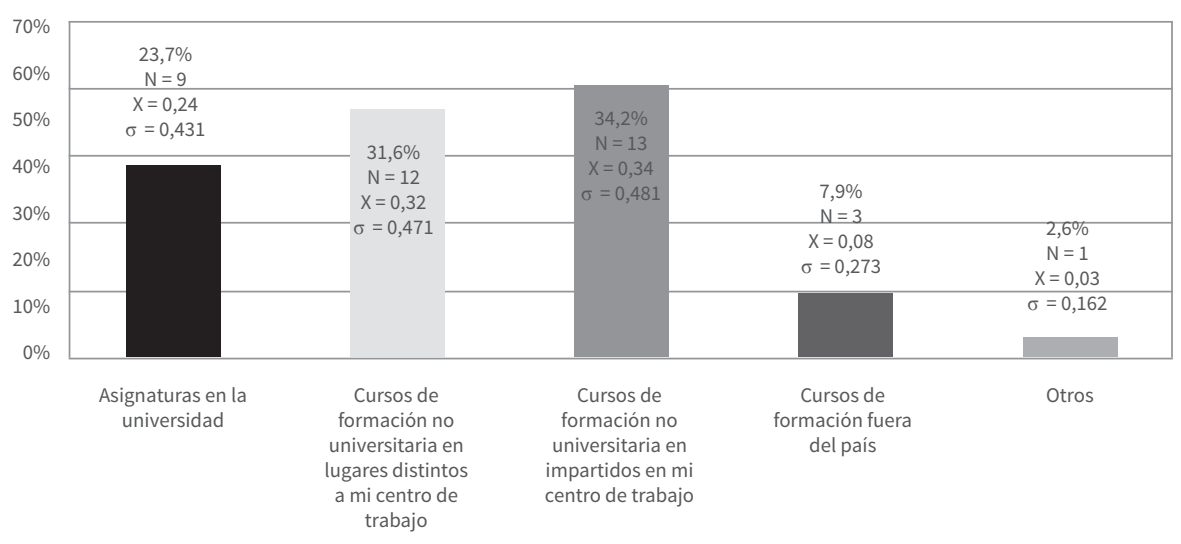

Fuente: elaboración propia.

Los periodistas encuestados, según puede apreciarse en la gráfica anterior, recibieron la mayor parte de los conocimientos sobre periodismo digital en cursos de formación no universitaria, dentro o fuera del centro de trabajo.

Pero a pesar de la preocupación de los medios ecuatorianos por brindar una formación especializada a sus comunicadores, el 76,32\% ( $n=29 ; x=0,24 ; \sigma=0,431)$ de los periodistas encuestados sostenía que no existía en sus medios un manual interno sobre el uso de las redes sociales, mientras que apenas un $23,68 \%$ ( $n=9 ; x=0,24 ; \sigma=0,431)$ de los informadores marcaron la opción afirmativa. Dicho manual, en el 55,6\% ( $\mathrm{n}=5$ ) de los casos, tenía en general dos años o menos, y solo en el 22,2\% (n=2) de las respuestas se subrayaba la existencia de un manual de uso de las redes con tres años o más; por último, el 22,2\% de los encuestados ( $\mathrm{n}=2$ ) no supo datar el establecimiento de ese insumo.

La inmensa mayoría de los periodistas encuestados, el 76,32\% ( $n=29 ; x=0,76 ; \sigma=0,431)$, respondió que les resultaría atractiva una oferta de capacitación profesional en el uso y manejo de las redes sociales. Por otro lado, el 23,68\% ( $n=9 ; x=0,76 ; \sigma=0,431)$ marcó la opción contraria. Al analizar las respuestas abiertas, encontramos que los términos más repetidos (con una frecuencia de cinco o más veces) son: "uso, manejo, herramientas". Estos términos, como vemos, están vinculados fundamentalmente a una capacitación sobre la gestión de las redes.

\subsection{Uso de redes}

A pesar de esta demanda formativa, las redes sociales se han integrado en la rutina habitual del periodista ecuatoriano participante en el estudio. El 86,84\% ( $\mathrm{n}=33 ; \mathrm{x}=3,84 ; \sigma=0,437)$ de los encuestados reconocía que tenían todo el día abiertas las aplicaciones vinculadas al consumo de redes sociales, o las usaban al menos una vez al día; el $10,53 \%(n=4 ; x=3,84 ; \sigma=0,437)$ frecuentaban las redes "varias veces a la semana", en tanto que solo un 2,63\% $(\mathrm{n}=1 ; \mathrm{x}=3,84 ; \sigma=0,437)$ indicaron que visitaban las redes esporádicamente. Si observamos atentamente la gráfica 
siguiente, casi todos los periodistas encuestados solían emplear más de un dispositivo para acceder a las redes sociales:

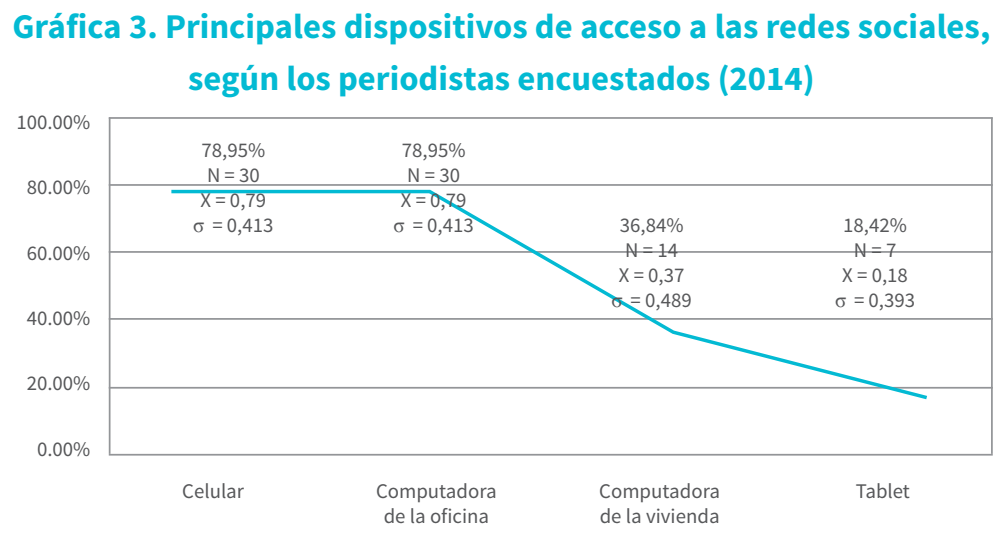

Fuente: elaboración propia.

Pero de los datos anteriores, subrayamos el hecho de que se duplicaba entre los periodistas el uso profesional sobre el uso doméstico. Sin embargo, casi la mitad de los encuestados, hasta el 44,74\% ( $n=17 ; \mathrm{x}=0,45 ; \sigma=0,504)$, no empleaba ningún programa para monitorizar y/o gestionar su actividad en las redes sociales; un 10,53\% ( $\mathrm{n}=4$; $\mathrm{x}=0,11 ; \sigma=0,311)$ no entendió la pregunta, y detectamos un 52,6\% $(\mathrm{n}=20)$ de los encuestados que sí utilizaban algún tipo de servicio de gestión de las redes, de los cuales el $31,58 \%(n=12 ; x=0,32 ; \sigma=0,471)$ frecuentaba TweetDeck, un 15,79 ( $\mathrm{n}=6 ; \mathrm{x}=0,16 ; \sigma=0,370)$ se decantó por Hootsuite, y un 5,26\% ( $\mathrm{n}=2 ; \mathrm{x}=0,05 ; \sigma=0,226)$ prefería emplear otras opciones. Ninguno de los encuestados marcó la opción reservada para SocialBro.

El $100 \%(n=38 ; x=1,00 ; \sigma=0,000)$ de los informadores de la muestra manejaba cuentas personales en las redes sociales, mientras que un $31,58 \%(n=12 ; x=0,32 ; \sigma=0,471)$ poseía además cuentas institucionales. Los usos que dan los periodistas a sus cuentas en las redes sociales están relacionados, particularmente, con una agilización de determinadas rutinas profesionales, y con una localización de críticas o de contenidos que pueden suscitar interés editorial

Los periodistas usan los medios sociales fundamentalmente para publicitar sus propios contenidos, par-

ticipar en redes, localizar nuevas noticias, contactar con fuentes sin necesidad de intermediarios, monito-

rizar lo que otros dicen de ellos o temas de su interés, identificar y verificar material, y publicar en tiempo

real. (Palomo, 2013, p. 119)

Sin embargo, al cuestionar a los periodistas ecuatorianos sobre qué usos daban a las redes sociales, observamos que la mayor parte de esos usos tenían un fuerte componente institucionalizado, al vincularse con actividades relacionadas con la promoción o la redifusión de los contenidos, y en menor medida a la interacción con las audiencias ${ }^{6}$ :

6 Se adjunta como anexo 1 un resumen descriptivo de la gráfica 4. 


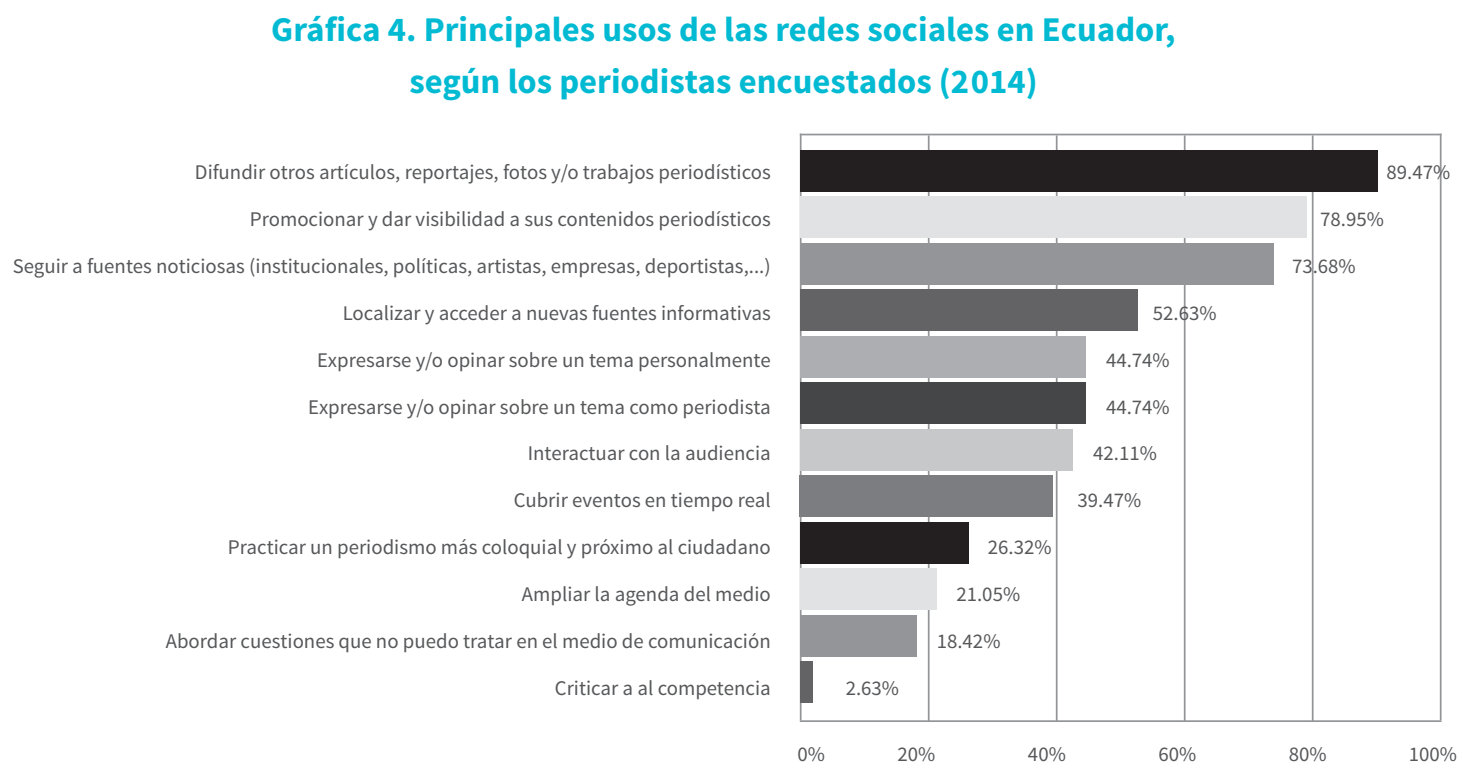

Fuente: elaboración propia.

Los datos ofrecidos en la gráfica anterior contrastan con los de países vecinos como Chile, donde el uso de las redes parece que está más vinculado al diálogo con las audiencias:

... los periodistas chilenos emplean Twitter no tanto para reportear o informar, sino para contactarse con sus seguidores, entablando conversaciones generalmente coloquiales. Esto implicaría (como objetivo final de una investigación de la cual se desprende este artículo) una exploración más profunda del uso de las redes sociales dentro de la labor periodística. (López-Hermida \& Claro, 2011, p. 31)

Las dos grandes plataformas de interacción con las audiencias eran, según los periodistas encuestados, el correo electrónico y Twitter, a pesar de que según el volumen de usuarios la red social más frecuentada en Ecuador es Facebook (Elcomercio.com, 2014, 17 de agosto): 
Tabla 2. Vías de interacción con las audiencias en Ecuador, según los periodistas encuestados (2014)

\begin{tabular}{|c|c|c|c|c|c|c|c|c|c|c|c|}
\hline & \multicolumn{2}{|c|}{$\begin{array}{c}\text { Una vez o } \\
\text { varias veces } \\
\text { al día }\end{array}$} & \multicolumn{2}{|c|}{$\begin{array}{l}\text { Varias veces } \\
\text { a la semana }\end{array}$} & \multicolumn{2}{|c|}{$\begin{array}{l}\text { Una vez a la } \\
\text { semana }\end{array}$} & \multicolumn{2}{|c|}{$\begin{array}{l}\text { Uso nulo de la } \\
\text { herramienta }\end{array}$} & \multirow{2}{*}{$\begin{array}{l}\text { Total } \\
\text { N }\end{array}$} & \multirow[t]{2}{*}{$\mathrm{x}$} & \multirow[t]{2}{*}{$\sigma$} \\
\hline & $\%$ & $\mathrm{~N}$ & $\%$ & $\mathrm{~N}$ & $\%$ & $\mathrm{~N}$ & $\%$ & $\mathrm{~N}$ & & & \\
\hline Correo electrónico & 76,3 & 29 & 5,3 & 2 & 0 & 0 & 0 & 0 & 31 & 0,87 & 0,475 \\
\hline Twitter & 65,8 & 25 & 10,5 & 4 & 2,6 & 1 & 5,3 & 2 & 32 & 1,16 & 0,916 \\
\hline Facebook & 52,6 & 20 & 13,2 & 5 & 2,6 & 1 & 21,1 & 8 & 34 & 1,71 & 1,334 \\
\hline YouTube & 50 & 19 & 13,2 & 5 & 5,3 & 2 & 7,9 & 3 & 29 & 1,24 & 1,125 \\
\hline Google+ & 23,7 & 9 & 15,8 & 6 & 2,6 & 1 & 21,1 & 8 & 24 & 1,47 & 1,538 \\
\hline $\begin{array}{l}\text { Comentarios en los } \\
\text { medios digitales }\end{array}$ & 21,1 & 8 & 21,1 & 8 & 5,3 & 2 & 13,2 & 5 & 23 & 1,32 & 1,397 \\
\hline Instagram & 15,8 & 6 & 7,9 & 3 & 2,6 & 1 & 34,2 & 13 & 23 & 1,76 & 1,777 \\
\hline Blogs & 10,5 & 4 & 7,9 & 3 & 15,8 & 6 & 23,7 & 9 & 22 & 1,68 & 1,694 \\
\hline Flickr & 52,6 & 20 & 2,6 & 1 & 0 & 0 & 80,9 & 17 & 21 & 0,58 & 0,552 \\
\hline
\end{tabular}

Fuente: elaboración propia.

El volumen de usuarios, según puede apreciarse en la tabla anterior, no está ligado a la frecuencia de uso; más bien hay factores predominantes, como la inmediatez que ofrece un servicio como el de Twitter, frente a un uso más reflexivo y personal que promueve Facebook. Asimismo, hemos detectado un tipo de interacción que tiende a evitar la división de las audiencias, al concentrar la mayor parte de la frecuencia de uso en unas plataformas específicas. En cuanto a los comentarios en los medios digitales, hay que subrayar que tras la aprobación de la Ley Orgánica de Comunicación, la mayor parte de los medios deshabilitaron las aportaciones de los usuarios, ante el problema de la responsabilidad legal, un problema que en cualquier caso forma parte de las cuestiones por resolver dentro de la comunicación digital y que afecta también a otros contextos geográficos (Singer \& Ashman, 2009). Los datos de la tabla 4 se complementan con los que presenta la gráfica que mostramos a continuación, en la cual hemos intentado cuantificar las acciones que realizan frecuentemente los periodistas ecuatorianos para dialogar con las audiencias?:

7 Se adjunta como anexo 2 un resumen descriptivo de la gráfica 7. 
Gráfica 5. Acciones que realizan a menudo los periodistas ecuatorianos para dialogar con sus audiencias, según los encuestados (2014)

Atender peticiones de cobertura noticiosa

Debatir cuestiones de actualidad

Responder a dudas/consultas

Responder a reclamos/quejas

Pedir ayuda a mis audiencias para una investigación periodística (por ejemplo localización de fuentes

Consultar a las audiencias sobre el trabajo periodístico realizado

Consultar a las audiencias sobre sus expectativas

Responder a críticas dirigidas contra el medio de comunicaciones o mi actividad periodística)

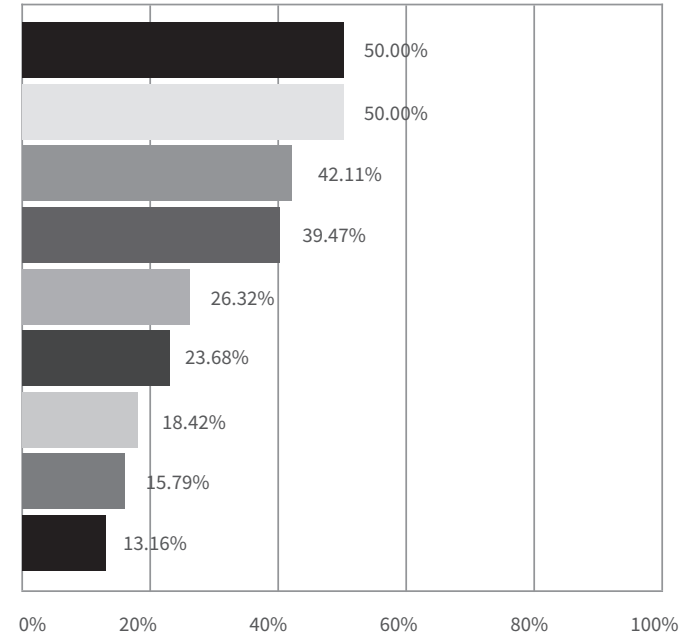

Fuente: elaboración propia.

Casi la mitad de los encuestados no se pronunció sobre los ítems de la pregunta, si bien los porcentajes de la tabla 2 son altos si los comparamos con un estudio realizado sobre un país vecino, en donde el $19 \%$ de los periodistas venezolanos consideraba que la tecnología "fomenta la interacción", mientras que el $27 \%$ aseguraba que "permite la instantaneidad" (Harris, Ríos \& Páez, 2011, p. 110-1).

El control de la calidad sobre el trabajo periodístico, según la opinión recogida, alcanzaba los menores porcentajes de entre todas las actitudes posibles, dentro del cual incluimos ítems como "responder a críticas dirigidas contra el medio o contra mi actividad periodística", o bien al que se refería a "consultar a las audiencias sobre sus expectativas". Tampoco registraban consensos significativos los ítems que recogían alusiones al periodismo participativo, como por ejemplo el de "pedir ayuda a mis audiencias para una investigación periodística (por ejemplo localización de fuentes).

\section{Las redes como fuentes}

Con respecto al uso de los contenidos informativos como fuentes, los periodistas encuestados reconocían emplear con mayor frecuencia los medios de comunicación tradicionales: 
Tabla 3. Frecuencias de empleo de los contenidos de diversos medios como fuentes informativas, según los periodistas encuestados (2014)

\begin{tabular}{|c|c|c|c|c|c|c|c|c|c|c|c|}
\hline & \multicolumn{2}{|c|}{$\begin{array}{c}\text { Muy } \\
\text { frecuentemente }\end{array}$} & \multicolumn{2}{|c|}{ A veces } & \multicolumn{2}{|c|}{$\begin{array}{c}\text { Poco, rara } \\
\text { vez }\end{array}$} & \multicolumn{2}{|c|}{ Nunca } & \multirow{2}{*}{$\begin{array}{c}\text { Total } \\
\text { N }\end{array}$} & \multirow[t]{2}{*}{$\mathrm{x}$} & \multirow[t]{2}{*}{$\sigma$} \\
\hline & $\%$ & N & $\%$ & N & $\%$ & $\mathrm{~N}$ & $\%$ & N & & & \\
\hline $\begin{array}{l}\text { Medios de } \\
\text { comunicación } \\
\text { tradicionales } \\
\text { (televisión, radio, } \\
\text { prensa) }\end{array}$ & 92,1 & 35 & 5,2 & 2 & 2,6 & 1 & 0 & 0 & 38 & 1,05 & 0,226 \\
\hline $\begin{array}{l}\text { Medios de } \\
\text { comunicación } \\
\text { digitales (cibermedios, } \\
\text { blogs) }\end{array}$ & 81,5 & 31 & 7,8 & 3 & 5,2 & 2 & 5,2 & 2 & 38 & 1,34 & 0,815 \\
\hline Redes sociales & 75 & 27 & 19,44 & 7 & 5,5 & 2 & 0 & 0 & 36 & 1,24 & 0,634 \\
\hline
\end{tabular}

Fuente: elaboración propia.

Las redes sociales registraron los menores porcentajes, e incluso motivaron la falta de respuesta de dos de los periodistas. Pero el predominio de las fuentes tradicionales no parecía ligado al factor de la credibilidad, en tanto que unos siete de cada diez encuestados opinaban que las redes sociales no eran ni más, ni menos creíbles que los medios de comunicación tradicionales: el 65,79\% ( $n=25 ; x=2,18 ; \sigma=0,512)$ de los periodistas marcó esta opción. Un 23,68\% de los encuestados ( $n=9 ; x=2,18 ; \sigma=0,512$ ) consideraba que las redes sociales eran menos creíbles que los medios tradicionales, mientras que el $5,26 \%(n=2 ; x=2,18 ; \sigma=0,512)$ otorgaba una mayor credibilidad a las redes, por el 5,26\% ( $n=2 ; x=2,18 ; \sigma=0,512)$ de esos encuestados que no lo tenían claro, de modo que prefirieron no responder. Esos bajos porcentajes son inherentes a las problemáticas asociadas al uso informativo de las redes sociales - como por ejemplo Twitter-como fuente:

... los periodistas latinos también son conscientes de las dificultades que deben sortear en el momento en que deciden usar información extraída de Twitter: ruido informativo, amarillismo, información falsa liberada a propósito, suplantación de identidad, dificultad para corroborar la autenticidad de un trino, sobresaturación, entre otros. (Cobos, 2010, p. 31)

Casi siete de cada diez encuestados, es decir, el 68,42\% ( $n=26 ; x=1,32 ; \sigma=0,471$ ) reconocían seguir habitualmente cuentas de Facebook o Twitter que consideraban como potenciales fuentes de información para su ejercicio periodístico, si bien el $31,58 \%(n=12 ; x=1,32 ; \sigma=0,471)$ sostuvieron que no utilizaban ese tipo de cuentas. En el caso concreto de Twitter, el 57,89\% ( $n=22 ; x=1,58 ; \sigma=0,500)$ de los periodistas no tenía listas, aunque el 42,11\% ( $\mathrm{n}=16 ; \mathrm{x}=1,58 ; \sigma=0,500)$ sí utilizaba este recurso.

Aparecer en las redes sociales tiene innumerables ventajas para los medios, según explica Palomo (2013, p. 118), hasta el punto de que esta investigadora -en el trabajo citado - afirma que dichos medios se encuentran "obsesionados" por ser protagonistas en las plataformas colaborativas. Hay algunas ventajas que favorecen esta 
situación, como la promoción de los contenidos o el elevado tráfico que pueden registrar, según Hong (cit. por Palomo, 2013, p. 18). Pero en el caso ecuatoriano, los medios a los que pertenecían los periodistas encuestados, según la tabla 3, tendían a no pronunciarse sobre el uso de estas plataformas mediáticas como fuentes informativas:

Gráfica 6. Opiniones del medio sobre el uso de redes sociales como fuentes informativas, según los periodistas encuestados (2014)

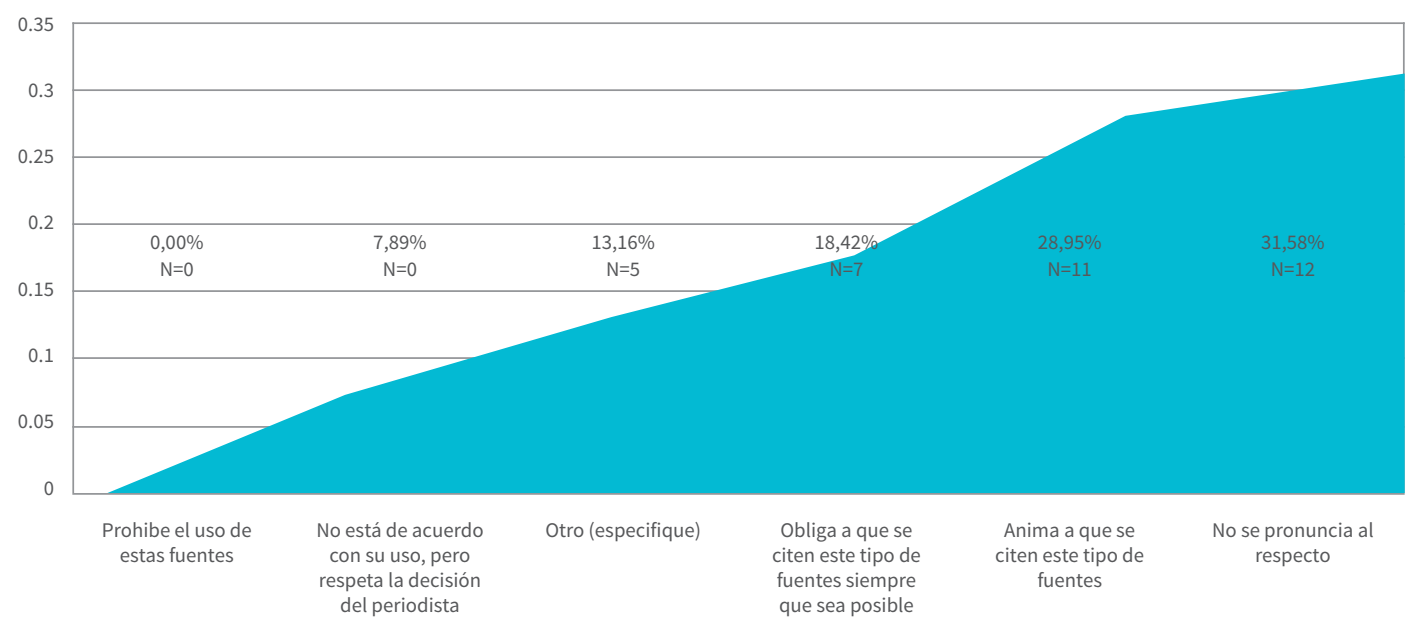

Fuente: elaboración propia.

La prohibición, a grandes rasgos, quedaba parcialmente excluida (solo aparecía en bajas frecuencias) sobre el empleo de ese tipo de fuentes. Los medios no recomendaban institucionalmente el uso de las redes sociales dentro de los recursos informativos, aunque incitaban su uso voluntario, según confirmamos en una pregunta complementariå:

8 Se adjunta como anexo 3 un resumen descriptivo de la gráfica 7. 
Gráfica 7. Acciones de los medios vinculadas a las redes sociales, según los periodistas encuestados (2014)

Recomienda que los periodistas, de forma voluntaria, utilicen las redes sociales

Incita a usar las redes sociales como fuentes de la labor periodística

Ha organizado cursos de formación en gestión de redes sociales

No posee ningún plan estratégico en materia de redes sociales

Exige que incremente el tráfico de mis artículos promocionando sus contenidos en redes sociales

Exige que dedique tiempo a atender a mis audiencias

Desconoce el potencial de las redes sociales

No está interesado en las redes sociales

Otorga un complemento salarial a los periodistas más activos en las redes sociales

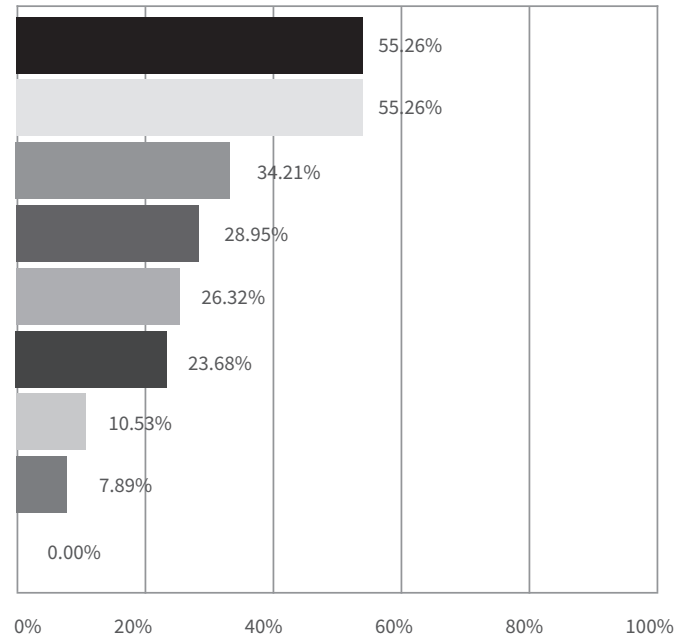

Fuente: elaboración propia.

Ninguno de los periodistas consultados afirmó cobrar un plus salarial por sus contribuciones a través de las redes sociales, algo que sí hacen otros medios internacionales sobre todo con los blogueros (Meso y Palomo, 2012). Si interpretamos la gráfica anterior, anotamos que apenas un tercio de los periodistas encuestados marcaron opciones concretas vinculadas al estímulo del empleo de las redes en el día a día profesional. Los principales canales que se empleaban en Ecuador como fuentes informativas, según la muestra interrogada, eran el correo electrónico, seguido por Twitter y Wikipedia:

Tabla 4. Frecuencia con la que se utilizaban los canales digitales como fuentes informativas, según los periodistas encuestados (2014)

\begin{tabular}{|c|c|c|c|c|c|c|c|c|c|c|c|}
\hline & \multicolumn{2}{|c|}{ Frecuentemente } & \multicolumn{2}{|c|}{ A veces } & \multicolumn{2}{|c|}{ Poco, rara vez } & \multicolumn{2}{|c|}{ Nunca } & \multirow{2}{*}{$\begin{array}{c}\text { Total } \\
\text { N }\end{array}$} & \multirow{2}{*}{$\mathrm{x}$} & \multirow{2}{*}{$\sigma$} \\
\hline & $\%$ & $\mathrm{~N}$ & $\%$ & $\mathrm{~N}$ & $\%$ & $\mathrm{~N}$ & $\%$ & $\mathrm{~N}$ & & & \\
\hline $\begin{array}{l}\text { Correo } \\
\text { electrónico }\end{array}$ & 84,3 & 27 & 12,5 & 4 & 0 & 0 & 3,1 & 1 & 32 & 1,03 & 0,716 \\
\hline Twitter & 68,5 & 24 & 17,1 & 6 & 5,7 & 2 & 8,5 & 3 & 35 & 1,42 & 1,004 \\
\hline Wikipedia & 55,1 & 16 & 13,7 & 4 & 13,7 & 4 & 17,2 & 5 & 29 & 1,47 & 1,330 \\
\hline Facebook & 45,4 & 15 & 18,1 & 6 & 18,1 & 6 & 18,1 & 6 & 33 & 1,82 & 1,312 \\
\hline YouTube & 53,5 & 15 & 7,1 & 2 & 14,2 & 4 & 25 & 7 & 28 & 1,55 & 1,465 \\
\hline Google+ & 36 & 9 & 4 & 1 & 8 & 2 & 52 & 13 & 25 & 1,82 & 1,753 \\
\hline Blogs & 29,6 & 8 & 25,9 & 7 & 22,2 & 6 & 22,2 & 6 & 27 & 1,68 & 1,454 \\
\hline
\end{tabular}




\begin{tabular}{|c|c|c|c|c|c|c|c|c|c|c|c|}
\hline & \multicolumn{2}{|c|}{ Frecuentemente } & \multicolumn{2}{|c|}{ A veces } & \multicolumn{2}{|c|}{ Poco, rara vez } & \multicolumn{2}{|c|}{ Nunca } & \multirow{2}{*}{$\begin{array}{c}\text { Total } \\
\mathrm{N}\end{array}$} & \multirow{2}{*}{$\mathrm{x}$} & \multirow{2}{*}{$\sigma$} \\
\hline & $\%$ & $\mathrm{~N}$ & $\%$ & $\mathrm{~N}$ & $\%$ & $\mathrm{~N}$ & $\%$ & $\mathrm{~N}$ & & & \\
\hline Flickr & 13,6 & 3 & 9,0 & 2 & 9,0 & 2 & 68,1 & 15 & 22 & 1,92 & 1,865 \\
\hline Instagram & 9,0 & 2 & 22,7 & 5 & 0 & 0 & 68,1 & 15 & 22 & 1,89 & 1,842 \\
\hline
\end{tabular}

Fuente: elaboración propia.

Del mismo modo que en los bloques anteriores, observamos que se utilizaban fundamentalmente las fuentes informativas textuales por encima de las audiovisuales. En general, los encuestados tendían a considerar un uso de las fuentes en función de la posibilidad de la redifusión de los contenidos; fue esta, según puede apreciarse en la siguiente gráfcia, la principal causa señalada9:

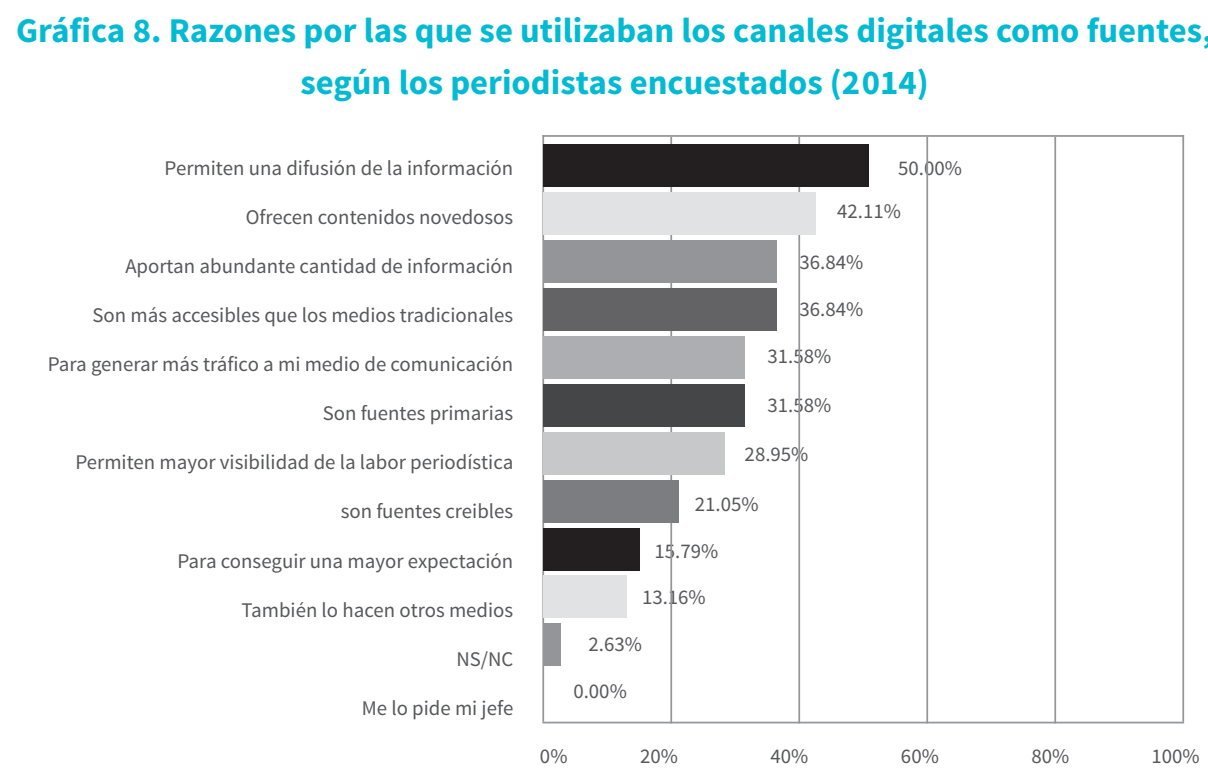

Fuente: elaboración propia

Las causas que propusimos en la gráfica anterior alcanzaron bajas frecuencias, prueba de que el empleo de las redes como fuentes informativas en 2014 era todavía incipiente.

9 Se adjunta como anexo 4 un resumen descriptivo de la gráfica 8. 
La mayoría de los informadores cuestionados siempre solían verificar el contenido localizado a través de una red social: el 89,47\% ( $\mathrm{n}=34 ; \mathrm{x}=1,11 ; \sigma=0,311)$ de los periodistas encuestados marcó esta opción, en tanto que el $10,53 \%(n=4 ; x=1,11 ; \sigma=0,311)$ reconoció que solo verificaban el contenido ocasionalmente. Las principales cuentas de redes sociales utilizadas como fuentes informativas estaban relacionadas con algún protagonista organizacional ${ }^{10}$ :

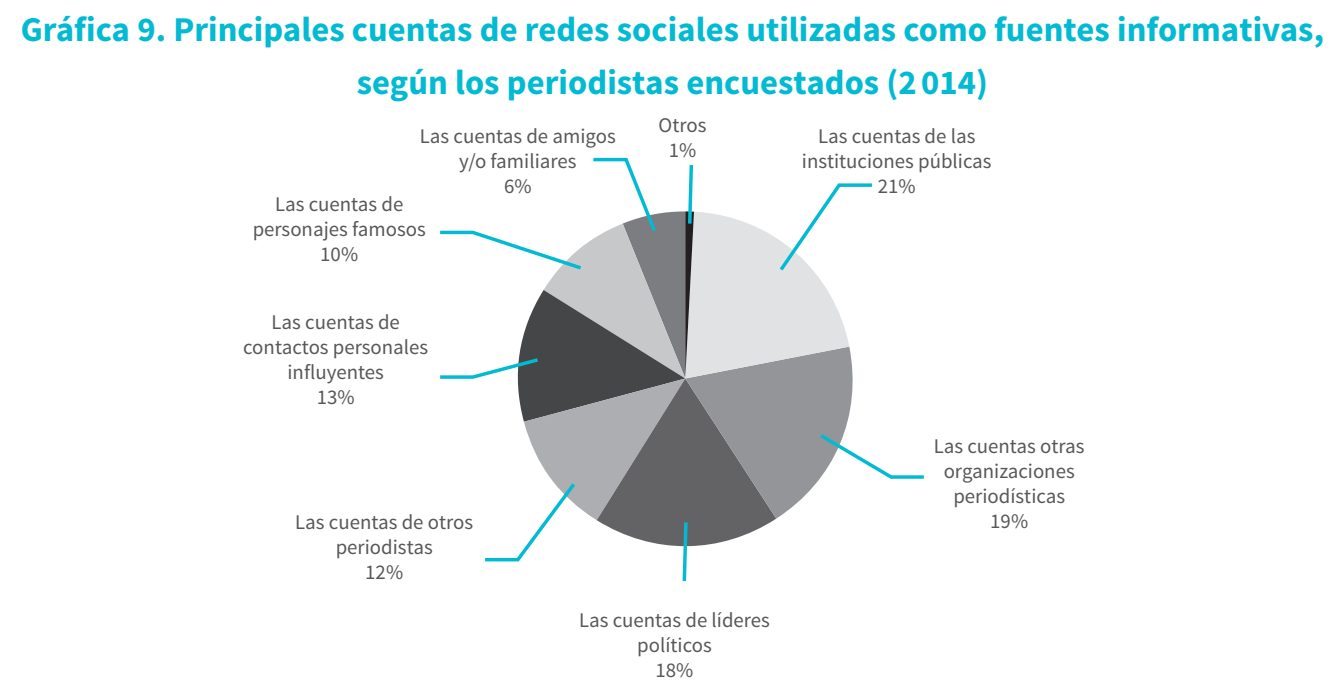

Fuente: elaboración propia.

Esos tres protagonistas -instituciones públicas, organizaciones periodísticas y líderes políticos - registraban el mayor consenso grupal, con una diferencia de más de veinte puntos con respecto de la consulta de cuentas de carácter individual.

\section{Conclusiones}

La importancia otorgada a la interacción con las audiencias - la cual establece la calidad de las conversacionesresulta determinante en un contexto global donde se incentivan las plataformas digitales como espacios de convivencia y en los que se prolonga el concepto habermasiano de esfera pública (Oller \& Barredo, 2012); y se fomenta la conversación como otrora sucedía en los cafés - en el siglo XIX- y en los periódicos -en el siglo XX-, según explican Ruiz, Domingo, Micó et ál. (2011). Dicha interacción fluctúa en función del contexto periodístico examinado, así como de la técnica de recolección de datos empleada; en el caso de Venezuela, por ejemplo, según el estudio de Harris, Ríos y Páez (2011, p. 116) el 100 \% de los informadores aseguraba conceder una gran importancia al contenido producido por los usuarios, y, en ese mismo estudio, nuevamente el $100 \%$ de los periodistas venezolanos subraya su interacción con los usuarios a través de la cuenta de Twitter. En Chile, sin embargo, el porcentaje de interacción descendía hasta el $61 \%$ de las conversaciones, según los datos revelados por un interesante estudio:

10 Se adjunta como anexo 5 un resumen descriptivo de la gráfica 9. 
El resto $(61 \%)$ comprende los diálogos que los periodistas entablan con otros miembros de la comunidad del Twitter en tiempo real. Fuera de ese contexto, no proveen información a aquellos interesados que no ingresen a la línea temporal de la conversación. Este considerable porcentaje sugiere que los periodistas entran en constante contacto con sus seguidores, mediante la pronta réplica de tweets previos. (López-Hermida \& Claro, 2011, p. 28)

En el caso ecuatoriano, hemos observado una baja interacción de los periodistas con sus audiencias, determinada en primer lugar por factores socioculturales: la baja participación en el espacio público convencional -según explicábamos en páginas anteriores - contagia inevitablemente a las rutinas de participación en el espacio público digital. En segundo lugar, la presencia de restricciones normativas - como las introducidas por la Ley Orgánica de Comunicación - estimula la aparición de un imaginario en donde los informadores tienden a adoptar estrategias de pasividad frente a las potenciales demandas sociales. Y ahí, ante ese comportamiento, resultaba clave la autorregulación de los medios; según nos reconocieron los periodistas, sus organizaciones no prohibían, pero tampoco estimulaban aspectos vitales como la interacción o el uso de las redes como fuentes informativas, a pesar de la importancia de ese tipo de participación, con la cual incluso ha sido posible efectuar el rescate de medios $^{11}$.

Dentro de los periodistas encuestados, anotamos la presencia de dos grupos referenciales, los cuales podrían inferir simbólicamente el estado de la cultura periodística digital en el Ecuador:

- Un primer grupo, predominante, de profesionales que desconocían en su mayor parte cómo enfrentarse a los retos digitales, debido tanto a causas educativas, como a circunstancias relacionadas con la edad, o la despreocupación o falta de estímulos de los medios.

- Un segundo grupo, minoritario, de profesionales que se habían formado esencialmente a través de cursos de formación no universitaria, y que conocían y utilizaban a menudo las herramientas digitales, aunque tendían a redirigir el tráfico al medio matriz online, quizá porque son conscientes de que el volumen de visitas resulta crucial en la "negociación de tarifas publicitarias" (Meso \& Palomo, 2012, p. 44). Asimismo, en este grupo, las actitudes detectadas, a grandes rasgos, no explotaban las posibilidades interactivas y participativas del nuevo entorno.

Todos estos rasgos determinaban la "etapa inicial" del periodismo participativo ecuatoriano (Rivera, 2011, p. 12), a pesar de que la gran limitación de este estudio es la imposibilidad de generalizar los resultados, en tanto que sería necesario emprender una muestra de tipo probabilístico o una mayor profundización en la relación que han de mantener los profesionales y las organizaciones con sus audiencias, tras el empoderamiento obtenido por los ciudadanos gracias a la democratización tecnológica. En este proceso de repensar las rutinas periodísticas dentro de Internet, creemos que habría que conseguir mayores incentivos tanto en el aparataje jurídico - toda vez que detectamos algunas lagunas, sobre todo vinculadas a la interacción, en la LOC-, como en las estructuras organizacionales y educativas. El objetivo de esos esfuerzos integrales sería forzar la desaparición de los posicionamientos monológicos, con el fin de gestionar una mayor integración colectiva dentro de los contenidos periodísticos, además de intensificar la redacción informativa según las estrategias narrativas digitales:

11 Para más información sobre este punto, se aconseja leer el texto de Sánchez y Palomo (2014, p. 109-110) donde se exponen algunos casos de medios rescatados por los ciudadanos a través de iniciativas como el crowdfunding. 
El gran desafío será ejercitar un periodismo de alta densidad, que combine los textos compactos con la presencia de detalles del hecho noticioso basado en la combinación del hiperenlaces, el multimedia y la organización no lineal del acontecimiento, que también delega en el lector la posibilidad de escoger el grado de profundidad que desea recorrer al explorar la pieza informativa. (Palomo, 2013, p. 127)

Recordemos que buscar nuevas fórmulas tiende a consolidar una mayor respuesta y, con ello, "un incremento de ventas o de usuarios/seguidores" (Sánchez \& Palomo, 2014: 102). Son ideas que, en cualquier caso, anotamos para desarrollar en un futuro próximo en estudios complementarios a este, en tanto que establecemos como posibles líneas a seguir la posibilidad de replicar este estudio en ámbitos locales o regionales, así como el interés por afrontar análisis desde técnicas cualitativas.

\section{Referencias}

1. Ander-Egg, E. (1993). Técnicas de Investigación Social (23a Ed.). Buenos Aires, Argentina: Magisterio del Río de La Plata.

2. Asa, A. (2014). Media and Communication Research Methods. An Introduction to Qualitative and Quantitative Approaches (3ra Ed.). Londres, Inglaterra: Sage.

3. Ávila, C. (2013). El sistema de comunicación en la Ley Orgánica de Comunicación del Ecuador: Un análisis desde el enfoque de las teorías de sociedad y masas de McQuail. Chasqui, Revista Latinoamericana de Comunicación, 124, 71-79.

4. Banco Mundial (s.f.). Abonados a Internet por banda ancha fija (por cada 100 personas). Recuperado el 18 de diciembre de 2014, de http://datos.bancomundial.org/indicador/IT.NET.BBND.P2/countries/1W-A5ZJ-EU?display=graph1

5. Barredo, D. (2013a). Siglo XXI y monarquía. Propuestas para dinamizar la caracterización informativa del rey Juan Carlos I. Área Abierta, 34 (3), 1-22.

6. Barredo, D. (2013b). La crisis de credibilidad de las organizaciones periodísticas: hacia la sociedad de los ideantes. Poliantea, IX (16), 101-126.

7. Barredo, D.; Oller, M. \& Buenaventura, S. (2013). The End of the Information Society. Notes for the Configuration of the New Contemporary Public Space: the Society of Devisers. Observatorio (OBS*) Journal, 7 (3), 079-091.

8. Barredo, D. \& Porto, A. (2014). CIESPAL, un punto de encuentro para las redes de investigación en América Latina (1959-2014). Diálogos en Red - Nuestra América, 1(1), 61-71.

9. Boczkowski, P. J. \& de Santos, M. (2007). When More Media Equals Less News: Patterns of Content Homogenization in Argentina's Leading Print and Online Newspapers. Political Communication, 24(2), 167-180.

10. Boczkowski, P. J.; Mitchelstein, E. \& Walter, M. (2011). Convergence Across Divergence: Understanding the Gap in the Online News Choices of Journalists and Consumers in Western Europe and Latin America. Communication Research, 38(3), 376-396. 
11. Bruns, A. (2008). "The Active Audience: Transforming Journalism from Gatekeeping to Gatewatching”. En: Paterson, Chris A. y Domingo, David (Ed.). Making Online News: The Ethnography of New Media Production (171-184). New York, Estados Unidos: Peter Lang.

12. Chirinos, E. (2006). Nuevas etapas evolutivas de los cibermedios: caso www.laverdad.com. Revista de Artes y Humanidades UNICA, 7(17), 109-137.

13. Cobos, T. L. (2010). Twitter como fuente para periodistas latinoamericanos. Razón y Palabra, 73, 1-35. Recuperado el 5 de diciembre de 2013, de http://www.razonypalabra.org.mx/N/N73/Varia73/33Cobos_ V73.pdf

14. Corbetta, P. (2007). Metodología y técnicas de investigación social. Madrid, España: McGraw-Hill.

15. Coronel, G.; Mier, C.; Barrazueta, P.; Ortiz, C.; González, V.; Yaguache, J.; Paladines, F.; Valarezo, K.; Banegas, D.; \& Samaniego, D. (2012). Morfología de los medios y empresas de comunicación del Ecuador. Revista Latina de Comunicación Social, 67. Recuperado el 16 de octubre de 2014, de http://www.revistalatinacs. org/067/art/966_Ecuador/22_Loja.html

16. Corrales, F. \& Hernández, H. G. (2009). La comunicación alternativa en nuestros días: un acercamiento a los medios de la alternancia y la participación. Razón y Palabra, 70. Recuperado el 20 de agosto de 2013 de https://razonypalabra.org.mx/N/N70/CORRALES-HERNANDEZ-REVISADO.pdf

17. Deuze, M. (2001). Online journalism: Modelling the first generation of news media on the World Wide Web. First Monday, 6 (10). Recuperado el 19 de octubre de 2012, de http://www.firstmonday.org/htbin/cgiwrap/ bin/ojs/index.php/fm/article/view/893/802

18. Díaz, D. R. (2000). Mediática e información digital en México. El medio digital frente a los "periódicos impresos", la radio y la televisión. Revista Latina de Comunicación Social, 31. Recuperado el 16 de agosto de 2013, de http://www.ull.es/publicaciones/latina/aa2000kjl/z31j//82david.htm

19. Elcomercio.com (2014, 17 de agosto). El uso de Internet en Ecuador creció 11 veces en siete años. Recuperado el 16 de octubre de 2014, de http://www.elcomercio.com/tendencias/ecuador-internet-datos-tecnologiausuarios.html

20. Franco, G. \& Guzmán, J. C. (2004, 22 de abril). The State of Online Journalism in Latin America. Recuperado el 19 de agosto de 2013, de http://www. poynter.org/uncategorized/22212/the-state-of-online-journalismin-latin-america/

21. García de Torres, E.; Yezers'ka, L.; Rost, A.; Calderin, M.; Rojano, M.; Sahid, E.; Jerónimo, P.; Arcila, C.; Serrano, A.; Badillo, J. \& Corredoira, L. (2011). See you on Facebook or Twitter? The use of social media by 27 news outlets from 9 regions in Argentina, Colombia, Mexico, Peru, Portugal, Spain and Venezuela. 12 international Symposium on Online Journalism. Abril, 1-2.

22. Gutiérrez, G. \& Páez, Á. (2012). Usabilidad en cibermedios nativos e inmigrantes. Temas de Comunicación, 24, 27-61.

23. Harlow, S. \& Harp, D. (2012). Collective action on the Web. Information, Communication \& Society, 15(2), 196-216.

24. Harris, A., Ríos, O. \& Páez, Á. (2011). El periodista venezolano en twitter. Disertaciones. Anuario Electrónico de Estudios en Comunicación Social, 4(2), 95-128. Recuperado el 5 de diciembre de 2013, de http://epublica. saber.ula.ve/index.php/Disertaciones/article/viewArticle/3044 
25. Hawkins, E. T. \& Hawkins, K. A. (2003). Bridging Latin America's Digital Divide: Government Policies and Internet Access. Journalism \& Mass Communication Quarterly, 80, 646-665.

26. Hernández, T.; López, X. \& Pereira, X. (2007). Cibermedios latinoamericanos: de la experimentación a la consolidación. Temas de Comunicación, 15, 31-45.

27. Hernández, Ó. (2004). Estadística elemental para Ciencias Sociales. San José, Costa Rica: Universidad de Costa Rica.

28. Holdom, S. (2005). E-Journal Proliferation in Emerging Economies: The Case of Latin America. Literary and Linguistic Computing, 20 (3), 351-365.

29. Hughes, S. \& Lawson, C. (2005). The Barriers to Media Opening in Latin America. Political Communication, $22(1), 9-25$.

30. Hueso, A. \& Cascant, M. J. (2012). Metodología y técnicas cuantitativas de investigación. Valencia, España: Universitat Politècnica de València.

31. Islas, O. (2006). El Empleo de Internet en el Desarrollo de las Campañas de los Candidatos a la Presidencia de México. Razón y Palabra, 51. Recuperado el 16 de agosto de 2013, de http://www.razonypalabra.org. mx/anteriores/n51/oislas.html

32. Jódar, J. (2010). La era digital: nuevos medios, nuevos usuarios y nuevos profesionales. Razón y Palabra, 71. Recuperado el 20 de agosto de 2013, de http://www.razonypalabra.orgwww.razonypalabra.org.mx/N/ N71/VARIA/29\%20JODAR_REVISADO.pdf

33. Katz, R. L. \& Ávila, J. (2011). La Infraestructura en el Desarrollo Integral de América Latina Diagnóstico estratégico y propuestas para una agenda prioritaria. Bogotá, Colombia: Corporación Andina de Fomento.

34. Ley Orgánica de Comunicación de 2013, Registro Oficial Número 22 de 21 de junio (2013). Recuperado el 29 de agosto de 2014, de http://www.asambleanacional.gob.ec/system/files/ley_organica_comunicacion. pdf

35. López, J. L. (2009). Estudio de servicios y productos ciberdocumentales en la prensa digital mexicana. Documentación de las Ciencias de la Información, 32, 93-132.

36. López-Hermida, A. \& Claro, C. (2011). Medios y periodistas en Twitter: el caso chileno. Correspondencias \& Análisis, 1, 17-33.

37. Meso, K. \& Palomo, M. B. (2012). The State of Blogging in Spanish Mainstream Media. Brazilian Journalism Research, 8(1), 35-47.

38. Milena, M. (2007). Los diarios digitales en América Latina: entre la revolución, la redefinición y la frustración. Investigación y Desarrollo, 15(2), 436-465.

39. Ministerio de Telecomunicaciones y de la Sociedad de la Información (2014, 19 de mayo). El 40,4\% de los ecuatorianos utilizó Internet en los últimos 12 meses. Recuperado el 20 de mayo de 2014, de http://www. telecomunicaciones.gob.ec/el-404-de-los-ecuatorianos-utilizo-internet-en-los-ultimos-12-meses/

40. Molloy, M. (2005). The Internet in Latin America. Journal of Library Administration, 43(3-4), 129-147.

41. Morales, F. (2000). Al rescate de la ciber-comunidad regional. El diario El Tiempo de Piura (Perú). Comunicación, 5. Recuperado el 16 de agosto de 2013, de http://pendientedemigracion.ucm.es/info/ periol/Period_I/EMP/Numer_07/7-4-Comu/7-4-05.htm 
42. Navarro, L. (2002). El Periodismo on-line en México. Razón y Palabra, 30. Recuperado el 16 de agosto de 2013, de http://www.www.razonypalabra.org.mx/anteriores/n30/Inavarro.html

43. Oller, M. \& Barredo, D. (2012). La Sociedad de los Ideantes: Repensando los conceptos de opinión y esfera pública y las teorías democráticas relacionadas con el fenómeno comunicativo ciudadano. Tenerife, España: Cuadernos Artesanos de la Latina.

44. Palacios, M.; Mielniczuk, S. B.; Ribas, B. \& Narita, S. (2002). Um mapeamento de características e tendências no jornalismo online brasileiro e português. Comunicarte, 1(2), 159-170.

45. Palomo, M. B. (2013). Claves de la implantación y la expansión del perfil social del periodista. Comunicación y Medios, 28, 113-129.

46. Paredes, M. L. (2011). Proceso de cambio político en Ecuador contemporáneo: un contrapunto con Venezuela. Quito, Ecuador: Abya - Yala.

47. Punín, M. I.; Martínez, A. \& Rencoret, N. (2014). Medios digitales en Ecuador: perspectivas de futuro. Comunicar, 42(XXI), 199-207.

48. Punín, M. I. \& Calva, K. D. (2014). Historia de los medios de comunicación en Ecuador. Aularia, Revista Digital de Comunicación, 2, 017-022.

49. Ramos, I. (2013). Trayectorias de democratización y desdemocratización de la comunicación en Ecuador. íconos. Revista de Ciencias Sociales, 45, 67-82.

50. Ramos, J. \& Gómez, A. (2014). Sujetos, objetos, decisiones y evasiones - el proceso de aprobación de la Ley de Comunicación en Ecuador. Intercom, Revista Brasileira de Ciências da Comunicação, 37 (1), 283-310.

51. Rivera, D. (2011). Evolución del ciberperiodismo en Ecuador a través de los periódicos de Loja. Razón y Palabra, 71. Recuperado el 15 de octubre de 2014, de http://wwww.razonypalabra.org.mx/N/N71/ VARIA/11\%20RIVERA_REVISADO.pdf

52. Rivera, J. (2013). Medios digitales en Ecuador, cuántos son y qué hacen. Chasqui, Revista Latinoamericana de Comunicación, 122, 111-117.

53. Rodríguez-Martínez, R.; Codina, L. \& Pedraza, R. (2010). Cibermedios y web 2.0: modelo de análisis y resultados de aplicación. El Profesional de la información, 19 (1), 35-44.

54. Ruiz, C.; Domingo, D.; Micó, J. L. et ál. (2011). "Public Sphere 2.0? The Democratic Qualities of Citizen Debates in Online Newspapers. The International Journal of Press/Politics, 16(4), 463-487.

55. Said, E. \& Arcila, C. (2011a). Los cibermedios en América Latina y la Web 2.0. Comunicar, 37(XIX), 125-131.

56. Said, E. \& Arcila, C. (2011b). Hacia un índice de medición del desarrollo de los cibermedios. Actas de la V Conferencia ACORN - REDECOM, Lima, 19 - 20 de Mayo, 1-9. Recuperado el 16 de agosto de 2013, de http:// www.acorn-redecom.org/papers/2011Hung_Espanol.pdf

57. Said, E. \& Arcila, C. (2011c). Líderes de opinión en Colombia, Venezuela e Irán. El caso de los 20 usuarios más vistos en Twitter. Comunicación y Sociedad, XXIV(1), 75-100.

58. Said, E. \& Arcila, C. (2012). El desarrollo de los cibermedios venezolanos. Investigación \& Desarrollo, 20 (2), 280-301.

59. Said, E. \& Valencia, J. (2012). Factores externos y rasgos estructurales que caracterizan el desarrollo de los cibermedios en América. Revista Española de Documentación Científica, 35(3), 414-432. 
60. Said, E., Arcila, C. \& Méndez, J. (2011). Desarrollo de los cibermedios en Colombia. El profesional de la información, 20 (1), 47-53.

61. Sánchez, F. (2008). ¿Democracia no lograda o democracia malograda? Un análisis del sistema político del Ecuador: 1979 - 2002. Quito, Ecuador: FLACSO.

62. Sánchez, M. \& Palomo, M. B. (2014). Conocimiento y valoración del "crowfunding” en Comunicación: La visión de profesionales y futuros periodistas. Comunicar, 43 (XXII), 101-110.

63. Schmitz, A. \& de Macedo, V. (2009). Compressed dimensions in digital media occupations. Journalists in transformation. Journalism, 10 (5), 587-603.

64. Schultz, T. (1999). Interactive Options in Online Journalism: A Content Analysis of 100 U.S. Newspapers. Journal of Computer-Mediated Communication, 5(1). Recuperado el 21 de agosto de 2013, de http:// onlinelibrary.wiley.com/doi/10.1111/j.1083-6101.1999.tb00331.x/full

65. Senplades (2013). Plan Nacional de Desarrollo / Plan Nacional para el Buen Vivir 2013 - 2017. Quito, Ecuador: SENPLADES.

66. Singer, J. B. \& Ashman, I. (2009). "Comment is Free, but Facts are Sacred”: User - generated Content and Ethical Constructs at the Guardian. Journal of Mass Media Ethics: Exploring Questions of Media Morality, 24 (1), 3-21.

67. Steensen, S. (2011). Online journalism and the promises of new technology. Journalism Studies, 12 (3), 311-327.

68. Torres, J. C. \& Infante, A. (2011). Desigualdad digital en la universidad: usos de Internet en Ecuador. Comunicar, 37 (XIX), 81-88.

69. Yezers ' ka, L. (2006). Los cibermedios en Perú. Revista Latina de Comunicación Social, 61. Recuperado el 16 de agosto de 2013, de http://www.revistalatinacs.org/_2008/07/200606_yudmyla.pdf

70. Yezers 'ka, L. (2008). Tendencias de los diarios digitales en Perú. Revista Latina de Comunicación Social, 63. Recuperado el 16 de agosto de 2013, de http://www.revistalatinacs.org/_2008/07/Lyudmyla.html

\section{Anexos}

Anexo 1. descripción de la Gráfica 4

\begin{tabular}{|l|c|c|c|c|}
\hline $\begin{array}{l}\text { Difundir otros artículos, reportajes, } \\
\text { fotos y/o trabajos periodisticos }\end{array}$ & 89,47 & 34 & 0,89 & 0,311 \\
\hline $\begin{array}{l}\text { Promocionary dar visibilidad a sus } \\
\text { contenidos periodísticos }\end{array}$ & 78,95 & 30 & 0,79 & 0,413 \\
\hline $\begin{array}{l}\text { Seguir a fuentes noticiosas } \\
\text { (institucionales, políticas, artistas, } \\
\text { empresas, deportistas...) }\end{array}$ & 73,68 & 28 & 0,74 & 0,446 \\
\hline $\begin{array}{l}\text { Localizary acceder a nuevas } \\
\text { fuentes informativas }\end{array}$ & 52,63 & 20 & 0,53 & 0,506 \\
\hline
\end{tabular}




\begin{tabular}{|l|c|c|c|c|}
\hline \multicolumn{1}{|c|}{$\begin{array}{c}\text { Expresarse y/o opinar sobre un } \\
\text { tema personalmente }\end{array}$} & 44,74 & 17 & 0,45 & 0,504 \\
\hline $\begin{array}{l}\text { Expresarse y/o opinar sobre un } \\
\text { tema como periodista }\end{array}$ & 44,74 & 17 & 0,45 & 0,504 \\
\hline Interactuar con la audiencia & 42,11 & 16 & 0,42 & 0,500 \\
\hline Cubrir eventos en tiempo real & 39,47 & 15 & 0,39 & 0,495 \\
\hline $\begin{array}{l}\text { Practicar un periodismo más } \\
\text { coloquial y próximo al ciudadano }\end{array}$ & 26,32 & 10 & 0,26 & 0,446 \\
\hline Ampliar la agenda del medio & 21,05 & 8 & 0,21 & 0,413 \\
\hline $\begin{array}{l}\text { Abordar cuestiones que no } \\
\text { puedo tratar en el medio de } \\
\text { comunicación }\end{array}$ & 18,42 & 7 & 0,18 & 0,393 \\
\hline Criticar a la competencia & 2,63 & 1 & 0,03 & 0,162 \\
\hline
\end{tabular}

Anexo 2. descripción de la Gráfica 5

\begin{tabular}{|l|c|c|c|c|}
\hline & $\%$ & N & X & 0 \\
\hline Responder a sugerencias & 50 & 19 & 0,50 & 0,507 \\
\hline $\begin{array}{l}\text { Atender peticiones de cobertura } \\
\text { noticiosa }\end{array}$ & 50 & 19 & 0,50 & 0,507 \\
\hline Debatir cuestiones de actualidad & 42,1 & 16 & 0,42 & 0,500 \\
\hline Responder a dudas/consultas & 39,5 & 15 & 0,39 & 0,495 \\
\hline Responder a reclamos/quejas & 26,3 & 10 & 0,26 & 0,446 \\
\hline $\begin{array}{l}\text { Pedir ayuda a mis audiencias para } \\
\text { una investigación periodística (por } \\
\text { ejemplo localización de fuentes) }\end{array}$ & 23,7 & 9 & 0,24 & 0,431 \\
\hline $\begin{array}{l}\text { Consultar a las audiencias sobre el } \\
\text { trabajo periodístico realizado }\end{array}$ & 18,4 & 7 & 0,18 & 0,393 \\
\hline $\begin{array}{l}\text { Consultar a las audiencias sobre } \\
\text { sus expectativas }\end{array}$ & 15,8 & 6 & 0,16 & 0,370 \\
\hline $\begin{array}{l}\text { Responder a críticas dirigidas } \\
\text { contra el medio de comunicación } \\
\text { o mi actividad periodística }\end{array}$ & 13,2 & 5 & 0,13 & 0,343 \\
\hline
\end{tabular}


Anexo 3. descripción de la Gráfica 7

\begin{tabular}{|c|c|c|c|c|}
\hline & $\%$ & $\mathrm{~N}$ & $\mathrm{x}$ & $\sigma$ \\
\hline $\begin{array}{l}\text { Incita a usar las redes sociales } \\
\text { como fuentes de la labor } \\
\text { periodística }\end{array}$ & 55,26 & 21 & 0,55 & 0,504 \\
\hline $\begin{array}{l}\text { Recomienda que los periodistas, } \\
\text { de forma voluntaria, utilicen las } \\
\text { redes sociales }\end{array}$ & 55,26 & 21 & 0,55 & 0,504 \\
\hline $\begin{array}{l}\text { Ha organizado cursos de } \\
\text { formación en gestión de redes } \\
\text { sociales }\end{array}$ & 34,21 & 13 & 0,34 & 0,481 \\
\hline $\begin{array}{l}\text { No posee ningún plan estratégico } \\
\text { en materia de redes sociales }\end{array}$ & 28,95 & 11 & 0,29 & 0,460 \\
\hline $\begin{array}{l}\text { Exige que incremente el tráfico de } \\
\text { mis artículos promocionando sus } \\
\text { contenidos en redes sociales }\end{array}$ & 26,32 & 10 & 0,26 & 0,446 \\
\hline $\begin{array}{l}\text { Exige que dedique tiempo a } \\
\text { atender a mis audiencias }\end{array}$ & 23,68 & 9 & 0,24 & 0,431 \\
\hline $\begin{array}{l}\text { Desconoce el potencial de las } \\
\text { redes sociales }\end{array}$ & 10,53 & 4 & 0,11 & 0,311 \\
\hline $\begin{array}{l}\text { No está interesado en las redes } \\
\text { sociales }\end{array}$ & 7,89 & 3 & 0,08 & 0,273 \\
\hline $\begin{array}{l}\text { Otorga un complemento salarial a } \\
\text { los periodistas más activos en las } \\
\text { redes sociales }\end{array}$ & 0 & 0 & 0 & 0 \\
\hline
\end{tabular}

Anexo 4. descripción de la Gráfica 8

\begin{tabular}{|c|c|c|c|c|}
\hline & $\%$ & $\mathrm{~N}$ & $\mathrm{x}$ & $\sigma$ \\
\hline $\begin{array}{l}\text { Permiten una difusión más rápida } \\
\text { de la información }\end{array}$ & 50 & 19 & 0,50 & 0,507 \\
\hline Ofrecen contenidos novedosos & 42,11 & 16 & 0,42 & 0,500 \\
\hline $\begin{array}{l}\text { Son más accesibles que los medios } \\
\text { tradicionales }\end{array}$ & 36,84 & 14 & 0,37 & 0,489 \\
\hline $\begin{array}{l}\text { Aportan una abundante cantidad } \\
\text { de información }\end{array}$ & 36,84 & 14 & 0,37 & 0,489 \\
\hline Son fuentes primarias & 31,58 & 12 & 0,32 & 0,471 \\
\hline $\begin{array}{l}\text { Para generar más tráfico a mi } \\
\text { medio de comunicación }\end{array}$ & 31,58 & 12 & 0,32 & 0,471 \\
\hline
\end{tabular}




\begin{tabular}{|l|c|c|c|c|}
\hline & $\%$ & N & X & 0 \\
\hline $\begin{array}{l}\text { Permiten una mayor visibilidad de } \\
\text { la labor periodística }\end{array}$ & 28,95 & 11 & 0,29 & 0,460 \\
\hline Son fuentes creíbles & 21,05 & 8 & 0,21 & 0,413 \\
\hline $\begin{array}{l}\text { Para conseguir una mayor } \\
\text { expectación }\end{array}$ & 15,79 & 6 & 0,16 & 0,370 \\
\hline También lo hacen otros medios & 13,16 & 5 & 0,13 & 0,343 \\
\hline NS / NC & 2,63 & 1 & 0,03 & 0,162 \\
\hline Me lo pide mi jefe & 0 & 0 & 0 & 0 \\
\hline
\end{tabular}

Anexo 5. descripción de la Gráfica 9

\begin{tabular}{|c|c|c|c|c|}
\hline & $\%$ & $\mathrm{~N}$ & $\mathrm{x}$ & $\sigma$ \\
\hline $\begin{array}{l}\text { Las cuentas de las instituciones } \\
\text { públicas }\end{array}$ & 73,68 & 28 & 0,74 & 0,446 \\
\hline $\begin{array}{l}\text { Las cuentas de otras } \\
\text { organizaciones periodísticas }\end{array}$ & 68,42 & 26 & 0,68 & 0,471 \\
\hline Las cuentas de líderes políticos & 63,16 & 24 & 0,63 & 0,489 \\
\hline Las cuentas de otros periodistas & 44,74 & 17 & 0,45 & 0,504 \\
\hline $\begin{array}{l}\text { Las cuentas de contactos } \\
\text { personales influyentes }\end{array}$ & 44,74 & 17 & 0,45 & 0,504 \\
\hline $\begin{array}{l}\text { Las cuentas de personajes } \\
\text { famosos }\end{array}$ & 34,21 & 13 & 0,21 & 0,413 \\
\hline $\begin{array}{l}\text { Las cuentas de amigos y/o } \\
\text { familiares }\end{array}$ & 21,05 & 8 & 0,08 & 0,273 \\
\hline Otro (especifique) & 2,63 & 3 & 1,11 & 0,311 \\
\hline
\end{tabular}

